\title{
Whiskey Tango Foxtrot: Technological Convergence?
}

\author{
Anne-Laure Mention \\ anne-laure.mention@rmit.edu.au | RMIT University, Australia \\ João José Pinto Ferreira \\ jjpf@fe.up.pt | INESC Technology and Science, Faculty of Engineering, University of Porto, Portugal \\ Marko Torkkeli \\ marko.torkkeli@lut.fi | Lappeenranta University of Technology, Finland
}

\section{Editorial}

Wisdom of the crowds, Technological capabilities and Functional alignment, which when recognised and utilised in innovation processes, can unlock the ability to source, develop and commercialise ideas at rapid pace. The phenomenon is known as technological convergence. By definition, technological convergence is described as the process by which Information and Communications Technologies (ICTs) converge towards new and more unified markets. This convergence often leverages the three dimensions of innovation - economic, technical and functional. On the economic side, the focus of a focal firm is on maximising profits with minimal costs under resource constraints brought about in-part by liberalisation of markets. In this regard, open innovation which involves harnessing wisdom of the crowds at the fuzzy front-end of the innovation process has increasingly been promoted as a pragmatic mechanism for accessing widely distributed knowledge (Thanasopon, Papdopoulos \& Vidgen, 2016), in large firms (Brunswicker \& Chesbrough, 2018) and SMEs (Vanhaverbeke, Frattini, Roijakkers \& Usman, 2018). On the technical side, the main driver has been the rise of enabling technologies, at times revolutioning social behaviour but mostly brought about through incremental shifts in technical abilities. Finally, convergence is realised through functional alignment, characterised by integration of computational, behaviour and communication factors in a unique value-proposition delivered through new product or new service (Canals, Torres \& Borés, 2001). The growing prominence of technological convergence means firms can no longer afford to work in silos or rely on proprietory waterfall solutions to achieve competitive advantage and influence societal progress. Here, we build on our July 2018 editorial which emphasised the cumulative importance of management research and management practice working together for societal progress. W-T-F is offered here as the fundamental trilogy that both managers and researchers need to address to survive and thrive in an increasingly digitised and globally-connected world. 
Traditionally, firms have relied more on their internal capabilities for R\&D, however in recent times, and especially since Chesbrough (2003) reignited the importance of wisdom of the crowds, a paradigmatic shift towards open innovation has been evident (Randhawa, Wilden \& Hohberger, 2016). For firms, open innovation aids in coping with three main challenges - technological pace, market and behaviour uncertainty and the need for complementing resources. The possibilities of convergence in an open innovation setting emerges as firms signal their intentions to achieve economies of scale through horizontal co-operation and structure the value chain to reach new markets and increase profitability through vertical co-operation. At a firm level, these cooperations involve adoption of platforms that allow for sourcing, developing, managing and integrating the wisdom of crowds into innovation, both in its process and as the eventual product. With a growing need to foster mediums that cater for dynamic inclusion and expression of ideas, opinions, judgements and evaluations, firms are starting to realise the potential of social media in and for innovation (Marion, Barczak \& Hultink, 2014; Pan et al., 2017). Social media in business not only serves as a mechanism to source ideas and and market products, but also helps to socialise, combine, externalise and internationalise knowledge across traditional boundaries (Scuotto, Del Giudice and Omeihe, 2017). But of course adoption of open and collaborative innovation processes require a shift in organisational mindset. Trust emerges as the core element of open innovation which at an inter-organisational level is about the trustworthiness of the crowd in general and close partners with whom the focal firm collaborates for innovation (Salampasis, Mention \& Torkkeli, 2014). If embedded in the innovation process, trust can foster openness and knowledge exchange to deliver results faster, with less costs and lower resource requirements for the focal firm.

Technical abilities are equally important as the slack in time-to-market and leveraging stakeholder inputs continues to reduce. The so-called enabling technologies have emerged as a solution to rapid design, develop and deploy strategies. Key Enabling Technologies (KETs) provide foundations for complementary cross-disciplinary, multi-sector innovations. Robotic process automation (RPA), artificial intelligence (AI), virtual reality (VR) and blockhain are some examples of KETs. They are the enablers that provide foundations for complementary cross-disciplinary, multi-sector innovations and are the fundamental building blocks of the Industry 4.0 and digitalisation. KETs help firms address the many concerns of driving manufacturing innovation increased global competition, mass customisation and resource limitations. The economic impact of KETs is considerable (see Baumers, Dickens, Tuck \& Hague,2016; Oesterreich \& Teuteberg, 2016). The challenge though is in sensemaking of the environment (i.e. what is out there) and then sensegiving through strategic actions that align required capabilities for the innovation to be realised.

Understanding where in the convergence process can the firm create the greatest impact is part of unravelling the challenge. Another plausible approach is to focus on the value streams to identify unique value propositions and shape the convergence process in iteself (e.g. something like what Apple did with Ipods and Microsoft did with its Windows CE). Open innovationas-a-service is an emerging trending. Firms are realising that static partnerships are no longer viable amidst converging markets and there exists a strong need to develop agile and dynamic collaborative platforms and ecosystems, inclusive of start-ups, innovation hubs, accelarators, co-working environments, universities, research centres and others (Chesbrough, Vanherbeke \& West, 2014). Often developing a more responsive business model begins with digitalisation of 
workflow. For instance, where data accumulated in files and mainframes is streamlined into real time cloud-based processing. An exemplar case is that of Siemens. Siemens has been using neural networks to monitor its steel plants and improve efficiencies for decades. Nearly two and half years ago, it introduced Mindsphere a smart cloud for industry - in direct competition to GE's Predix. Mindsphere allows machine manufacturers to monitor machine fleets and servicing throughout the world. AI integrated in the turbines continuously learns the optimal combustion conditions through sensors and the result of this technological convergence is that Siemens has been able to reduce emissions in its gas turbines. The logic advanced through this example is that by converging workflow management with real-time decision-making and data capture capabilities can improve efficiencies and cost savings across a wide range of automation tasks. The underlying objective is to free human capital from performing repetitive mundane tasks and allow cognitive capacities to focus on problem solving, judgement and creativity tasks.

Once again, the need emerges to firms to foster organisational culture for innovation. This may mean obvious tasks of developing cross-disciplinary skills and fostering cross-cultural integration but it also calls for strategic signalling strategies to drive efficient open and collaborative processes (Constantiou \& Kallinikos, 2015). These signals need to be aimed at blurring the long-established social, cognitive, organisational and functional boundaries, whereby the spatial distance between factors influencing human-side of innovation (Salampasis \& Mention, 2017) are radically reframed. Nelson and Winter $(1982,2002)$ emphasised the need for organisational routines to conceive and crystallise the business-as-usual operating processes. Routines are a way to signal firm's appetite for learning from local and distance experiences or events (Nelson \& Winter, 1982) and when treated as building blocks of organisation's core capabilities, they can provide important input into the strategic choices (Dosi, Nelson \& Winter, 2001). Routines may be enacted through patenting process, venture sourcing processes, development of experimental test beds, cross-disciplinary collaborations, recognition and award programs, technological roadmapping and business foresight to name a few. Indeed, as Teece (2007) highlights, the strategic intent of a focal firm is often a reflection of the 'best fit' of its capabilities and the opportunities arising from the environmental scanning. Convergence trends tend to curate the sensemaking and road mapping strategies as firms move towards agile innovation methods encompassing generative work relationships to drive futuristic scenarios (Carmeli \& Dothan, 2017).

By becoming more agile firms stand to benefit from improved ability to make sense and respond to customer-centric product development opportunities arising from technological convergence (Cardinal, Turner, Fern \& Burton, 2011; Porter \& Heppelmann, 2015). Over the next ten years a number of key trends and drivers are likely to influence KETs and their potential to revolutionise the way people, industry and society will behave from an economic, social, cultural and environmental perspective. Many broad societal factors will interact with KETs - increasing globalisation, change in customer demands and regulatory attitudes. A key challenge for firms in attracting, developing and retaining the right individuals with cross-disciplinary skills (the so-called T-shaped individuals) to remain relevant and drive profits. In this view, the scholarly work on university-industry collaboration (UIC) triple helix model (Calvert \& Patel, 2003)is of particular relevance. Much has been said about the motivations and mechanisms for promoting UIC (Rasmussen \& Sørheim, 2012; Temel \& Glassman, 2013) as well as patterns and performance of UIC (Al-Ashaab et al., 2011; Ngar-yin Mah \& Hills, 2014). Yet, little has been said about how technological convergence is shaping UIC and development of the next cohort of human 
capital. While some efforts have been made to understand which technologies fields are central to UIC (see Chang, 2017), many questions remain unanswered in relation to requirements for new curricula.

Naturally, the courses taught at universities should aim to assimilate new technology and talent trends alongside the appetite for breadth of knowledge rather than deepening disciplinary silos. As Kose and Sakata (2018) recently highligted, technological convergence in itself can be leveraged as a promoter of introduction to new skills sets, markets and sectors. Arguably, this calls for managers and academics to know what is out there, building 'work ready' skills and a culture of experimentation and entrepreneurial mindset - pushing the boundaries of ordinary to 'extra'ordinary thought and actions. An important paradigm in this view is to bring about a change in traditional university structures and education programs based on 'academic mastery' towards a more 'education-as-a-service' model. This shift is more than an university setting up innovation labs or a firm hiring university researchers to solve a problem. The shift to the new UIC paradigm of 'education-as-a-service' calls for deeper subject-matter training and fostering an entrepreneurial mindset whilst engaging learners in cross-disciplinary problem solving through targeted strategic partnerships, to deliver value as licensable products or services designed for societal progress. It may be so that the focus now needs to shift towards harnessing the convergence rather than solving a technological puzzle. Alignment and effective partnerships coupled with open and collaborative knowledge exchange environments remain providential for profits and progress.

For researchers, we draw attention to the role of managers and managerial cognition in innovation management. To understand how technological convergence is perceived, promoted and managed requires a closer examination of how external enviroment shapes a firm's strategy. The information collected from the environment in the process of scanning only becomes meaningful through interpretations and mental processes of the managers responsible for shaping a firm's strategy (Gavetti \& Rivkin, 2007). In this view even organisational routines for innovation can be considered intrinsically linked to managerial cognition through interpretations of scenarios and strategic choices (Eggers \& Kaplan, 2013). For practitioners we call for a developing a stronger voice. This voice needs to be purposefully directed to harness convergence and find ways to collaborate with universities in developing industrially relevant curricula and training programs. Developing platforms of knowledge exchange and strategic partnerships should remain a priority for managers to source and nurture talent. Symbolically, co-working spaces, innovation hackathons, participation in behavioural and cultural intelligence workshops and industrial $\mathrm{PhD}$ programs are some examples of cultivating a new mindset to routines and future of work. In summary, the task ahead brought about by technological convergence cannot be achieved through traditional methods. New and agile approaches are needed both from a research and practice perspective. Agility in innovation management can be infectious (Kahan, 2018), but requires a shift in mindset to look at problems in different ways, at times crushing the core assumptions and determining the true goals of work. In this view, W-T-F provide a basic yet valuable framework to advance science and practice of innovation.

Yours innovatively,

Anne-Laure Mention, João José Pinto Ferreira, Marko Torkkeli

Editors 


\section{References}

Al-Ashaab, A., Flores, M., Doultsinou, A. and Magyar, A., 2011. A balanced scorecard for measuring the impact of industry-university collaboration. Production Planning 86 Control, 22 (56), pp.554-570.

Baumers, M., Dickens, P., Tuck, C. and Hague, R., 2016. The cost of additive manufacturing: machine productivity, economies of scale and technology-push. Technological Forecasting and Social Change, 102, pp.193-201.

Brunswicker, S. and Chesbrough, H., 2018. The Adoption of Open Innovation in Large Firms: Practices, Measures, and Risks A survey of large firms examines how firms approach open innovation strategically and manage knowledge flows at the project level. Research-Technology Management, 61(1), pp.35-45.

Calvert, J. and Patel, P., 2003. University-industry research collaborations in the UK: bibliometric trends. Science and public policy, 30(2), pp.85-96.

Canals, C.S., Torres, R. and Borés, C., 2001. Technological convergence: a strategic perspective. Documents de Treball del Departament d'Economia (Universitat de Girona), 2, pp.131.

Cardinal, L.B., Turner, S.F., Fern, M.J. and Burton, R.M., 2011. Organizing for product development across technological environments: Performance trade-offs and priorities. Organization Science, 22(4), pp.1000-1025.

Carmeli, A. and Dothan, A., 2017. Generative work relationships as a source of direct and indirect learning from experiences of failure: Implications for innovation agility and product innovation. Technological Forecasting and Social Change, 119, pp.27-38.

Chang, S.H., 2017. The technology networks and development trends of university-industry collaborative patents. Technological Forecasting and Social Change, 118, pp.107-113.

Chesbrough, H., 2003. The logic of open innovation: managing intellectual property. California Management Review, pp.33-58.

Chesbrough, H., Vanhaverbeke, W. and West, J. eds., 2014. New frontiers in open innovation. London: Oxford.

Constantiou, I.D. and Kallinikos, J., 2015. New games, new rules: big data and the changing context of strategy. Journal of Information Technology, 30(1), pp.44-57.

Dosi, G., Nelson, R. and Winter, S. eds., 2001. The nature and dynamics of organizational capabilities. London: Oxford.

Eggers, J.P. and Kaplan, S., 2013. Cognition and capabilities: A multi-level perspective. Academy of Management Annals, 7(1), pp.295-340.

Gavetti, G. and Rivkin, J.W., 2007. On the origin of strategy: Action and cognition over time. Organization Science, 18(3), pp.420-439. 
Kahan, S. 2018. The Age of Agile: a guide to a revolution in innovation management. Strategy \& Leadership, 46(2), pp. 48-49.

Kose, T. and Sakata, I., 2018. Identifying technology convergence in the field of robotics research. Technological Forecasting and Social Change. (In press).

Marion, T.J., Barczak, G. and Hultink, E.J., 2014. Do social media tools impact the development phase? An exploratory study. Journal of Product Innovation Management, 31, pp.18-29.

Nelson, R.R. and Winter, S.G., 1982. The Schumpeterian tradeoff revisited. The American Economic Review, 72(1), pp.114-132.

Nelson, R.R. and Winter, S.G., 2002. Evolutionary theorizing in economics. Journal of Economic Perspectives, 16(2), pp.23-46.

Ngar-yin Mah, D. and Hills, P., 2014. Collaborative governance for technological innovation: a comparative case study of wind energy in Xinjiang, Shanghai, and Guangdong. Environment and Planning C: Government and Policy, 32(3), pp.509-529.

Oesterreich, T.D. and Teuteberg, F., 2016. Understanding the implications of digitisation and automation in the context of Industry 4.0: A triangulation approach and elements of a research agenda for the construction industry. Computers in Industry, 83, pp.121-139.

Pan, Z., Lu, Y., Wang, B. and Chau, P.Y., 2017. Who Do You Think You Are? Common and Differential Effects of Social Self-Identity on Social Media Usage. Journal of Management Information Systems, 34(1), pp.71-101.

Porter, M.E. and Heppelmann, J.E., 2015. How smart, connected products are transforming companies. Harvard Business Review, 93(10), pp.96-114.

Randhawa, K., Wilden, R. and Hohberger, J., 2016. A bibliometric review of open innovation: Setting a research agenda. Journal of Product Innovation Management, 33(6), pp.750-772.

Rasmussen, E. and Sørheim, R., 2012. How governments seek to bridge the financing gap for university spin-offs: Proof-of-concept, pre-seed, and seed funding. Technology Analysis 63 Strategic Management, 24 (7), pp.663-678.

Salampasis, D. and Mention, A.L., 2017. Open Innovation: Unveiling the Power of the Human Element. Singapore: World Scientific Publishing Co.

Salampasis, D., Mention, A.L. and Torkkeli, M., 2014. Open innovation and collaboration in the financial services sector: exploring the role of trust. International Journal of Business Innovation and Research, 8(5), pp.466-484.

Scuotto, V., Del Giudice, M. and Obi Omeihe, K., 2017. SMEs and mass collaborative knowledge management: toward understanding the role of social media networks. Information Systems Management, 34 (3), pp.280-290.

Teece, D.J., 2007. Explicating dynamic capabilities: the nature and microfoundations of (sustainable) enterprise performance. Strategic Management Journal, 28(13), pp.1319-1350.

Temel, S. and Glassman, B., 2013. Examining university-industry collaboration as a source of 
innovation in the emerging economy of Turkey. International Journal of Innovation Science, 5(1), pp.81-88.

Thanasopon, B., Papadopoulos, T. and Vidgen, R., 2016. The role of openness in the fuzzy front-end of service innovation. Technovation, 47, pp.32-46.

Vanhaverbeke, W., Frattini, F., Roijakkers, N. and Usman, M., 2018. Researching Open Innovation in SMEs. Singapore: World Scientific.

Cite paper as: Mention, A., Pinto Ferreira, J.J., Torkkeli , M., (2018). Whiskey Tango Foxtrot: Technological Convergence? - Editorial, Journal of Innovation Management, www.open-jim.org, 6(3), 1-7. http://hdl.handle.net/10216/116396 